\title{
Production of Macrocyclic Polyether Benzo-15-Crown-5 and its Functional Derivatives
}

\section{VALENTINA N. GLUSHKO*, NATALYA YU. SADOVSKAYA, VADIM I. KOZHUHOV, LIDIYA I. BLOKHINA, IRINA A. ANTROPOVA, EKATERINA S. PETINA, VASILIY M. RETIVIOV and EKATERINA YU. MELNIKOVA}

The Federal State Unitary Enterprise «Institute of Chemical Reagents and High Purity Chemical Substances of National Research Centre «Kurchatov Institute», Bogorodsky val str.3, Moscow.

${ }^{*}$ Corresponding author e-mail; tetrazoli @ yandex.ru

http://dx.doi.org/10.13005/ojc/330413

(Received: April 06, 2017; Accepted: June 06, 2017)

\begin{abstract}
Study of interaction between catechol and tetraethylene glycol dichloride in the n-butanol media, resulting with benzo-15-crown-5 production. Production of nitro- and amino-derivatives of benzo-15-crown-5. Determination of their thermogravimetric characteristics.
\end{abstract}

Keywords: benzo-15-crown-5, catechol, tetraethylene glycol dichloride, crown ether, gas liquid chromatography, chromate-mass spectrometry

\section{INTRODUCTION}

The results of studying crown ethers, which were discovered in 1962, allowed to reveal their properties ensuring their successful use for solving issues in various fields of science, medical practice and modern manufacturing. A unique property of crown ethers is their high selectivity in terms of forming host-guest complexes formation with metal ions and neutral organic molecules. Such interaction is specific and determined by both electronic and topological factors, which opens broad prospects for using crown ethers as highly selective splitters, carriers, catalyst and the like ${ }^{1-6}$. These properties has already helped crown ethers secure their place in medicine $^{7}$, botany ${ }^{8}$, engineering and technology ${ }^{9}$.

It is possible to synthesize crown-etherbased adsorbing agents, and their adsorbing ability could be further improved due to the crown-ether fragments chemically attached to them. Non-soluble polymers with crown units in their backbone or side chains turn out to be preferable over their monomer analogues, since they are easier to process, regenerate and reuse.

For example, adding of ether groups to chloromethylated styrene/divinylbenzene copolymer 
enabled the prodution of electrodialysis membranes capable of alkali metal chlorides adsorbing and releasing them after slight temperature increase.

Amino- and diamino-crown ethers and nitrogen-containing heterocyclic compounds suitable for further functional improvement. are of particular interest, since their compounds which are suitable can immobilize into various organic and non-organic carriers and act as an initial material for forming new nitrogen-containing structures formation.

Amino-substituted crown compounds can also undergo acylation, phosphorylation, addition, condensation, alkylation and arylation reactions, as well as form isocyanates under phosgene effect and can be immobilized on carrier surface ${ }^{3}$.

Despite growing interest in these compounds over recent years, the current number of papers on the synthesis of macrocyclic polyethers is extremely small ${ }^{10-15}$. For example, benzo-15-crown-5 can be produced using Williamson synthesis reaction, featured by interaction between catechol (orto-dihydroxybenzene) and tetraethylene glycol dichloride (1,10-dichloro-3,6,9-trioxadecane) over sodium hydroxide in the n-butanol media (30-h inertatmosphere boiling). The yield of benzo-15-crown-5 produced by this method is $62 \%$, with the basic substance's mass fraction of $95 \%$.

Nitro-derivative B15C6 is produced by also applying $76 \% \mathrm{HNO}_{3}$ in a glacial acetic acid. This method was used for producing 4'-nitroB18C6, 4'- nitro-B15C5 and 4',5'-dinitro-B15C5 and nitro-derivatives $\mathrm{B} 18 \mathrm{C} 6$ respectively ${ }^{16}$. Mononitroderivatives $\mathrm{B} 18 \mathrm{C} 6$ and $\mathrm{B} 15 \mathrm{C} 5$ too were also synthesized using $58 \% \mathrm{HNO}_{3}$ in acetonitrile ${ }^{17}$.

The relevant literature contains only a few main methods of producing amino-derivatives of benzo- and dibenzo-crown ethers production. In one of their latest papers ${ }^{18}$ the authors reduced dinitroderivatives of crown ethers by hydrazine hydrate over palladium on carbon in the diethylene glycol dimethyl ether media.

In case of paper ${ }^{19}$, the reduction was carried out over palladium on carbon in dimethylformamide, with its duration and pressure of $1.75 \mathrm{~h}$ and 1551.49 torr respectively.

Feigenbaum and Michel ${ }^{20}$ produced cisand trans-isomers of diaminodibenzo-18-crown-6 by hydrogenating corresponding individual dinitroisomers in the form of suspension over Raney nickel in dimethylformamide, using pressurized hydrogen. Figure 1 shows 4-aminobenzo-15-crown- 5 synthesis scheme.

\section{MATERIALS AND METHODS}

A series of experiments was conducted to determine the optimal conditions for performing benzo-15-crown-5 production reactions.

For the purpose of ensuring of selective behavior of cyclization reaction, which results in cyclic compounds, and inhibiting side reactions that lead to formation of linear polymers, a high dilution method is used for synthesizing crown ethers, since the formation of macrocyclic product through intramolecular reaction in diluted solutions is more likely, thus process will be faster than polymer formation, which requires collisions between two reagents (intermolecular reaction) ${ }^{21-22}$.

Since sodium hydroxide is used as a template agent in production process, the method of adding tetraethylene glycol dichloride (TEGDC) addition plays an important role, due to its possible hydrolysis in the alkali media. Therefore, three methods of this reagent addition to the reaction (dropwise addition; adding 1/3 of tetraethylene glycol dichloride amount every ten minutes; and adding the whole amount of tetraethylene glycol dichloride at once) were studied. A thermodynamic condition of the reaction mixture during dichloride addition varied too.

The following reagents were using for synthesizing benzo-15-crown-5: catechol, 99.6\% (manufacturer: Merck); tetraethylene glycol dichloride, 98.5\%; n-butanol, 99.5\%; sodium hydroxide, 99.5\%; hydrochloric acid, 38\%; and pure-grade hexane.

Benzo-15-crown-5 synthesis (Synthesis 1: dropwise addition of tetraethylene glycol dichloride). 


\section{General procedure}

$88 \mathrm{~g}$ (0.8 mole) catechol and $1200 \mathrm{ml}$ n-butanol was plased into a 2-liter flask equipped with a mechanical stirrer, thermometer, water condenser and dropping funnel was placed. After dissolution of the catechol by stirring, aqueous $\mathrm{NaOH}$ solution ( $67.2 \mathrm{~g} \mathrm{NaOH}$ to $80 \mathrm{ml} \mathrm{H}_{2} \mathrm{O}$ ) was added. Mixing duration was 30 to 40 minutes. After $156.6 \mathrm{ml}$ (0.8 mole) tetraethyleneglycol dichloride was dripped through dropping funnel at $17 \mathrm{ml} / \mathrm{min}$ rate. The mixture was refluxed for 7 hours $\left(107^{\circ} \mathrm{C}\right)$. After that, the filtrate was acidified with concentrated hydrochloric acid, filtered off and flushed with water until neutral reaction was reached. Upper organic layer was put into round-bottom flask, treated with activated carbon and filtered off. Then the filtrate was boiled out using rotary evaporator, accompanied by complete solvent distillation. The residue was extracted with hexane, followed by producing white transparent crystals of benzo-15-crown-5.

Infrared spectrum $\left(\mathrm{KBr}, v, \mathrm{~cm}^{-1}\right): 468$ (weak), 514 (weak), 538 (weak), 602 (weak), 740 (strong) (aromatic C-H), 779 (weak), 851 (medium), 906 (weak), 938 (strong) (aromatic C-H), 980 (weak), 1042 (medium), 1051 (strong), 1076 (medium), 1094 (medium), 1121 (strong) (C-O-C), 1130 (strong) (C-O-C), 1226 (strong) (aromatic C-H), 1261 (strong) (aromatic C-H), 1269 (medium), 1335 (medium), 1345 (medium), 1362 (weak), 1412 (weak), 1455 (medium), 1509 (strong) $\left(\mathrm{CH}_{2}\right), 1593$ (medium), 2863 (strong) (C-H), 2920 (strong) (C-H), 2940 (strong) (C-H), 3009 (weak) (C-H aromatic), 3036 (weak) (C-H aromatic), 3060 (weak) (C-H aromatic)
${ }_{1} \mathrm{H}$ Nuclear magnetic resonance (DMSO-d, $300 \mathrm{MHz}$ ): 3.62 (broad singlet, $8 \mathrm{H}$, $\mathrm{CH}_{2}+\mathrm{CH}_{2}+\mathrm{CH}_{2}+\mathrm{CH}_{2}$ ), 3.73-3.81 (multiplet, $4 \mathrm{H}$, $\mathrm{CH}_{2}+\mathrm{CH}_{2}$ ), 4.00-4.09 (multiplet, $4 \mathrm{H}, \mathrm{CH}_{2}+\mathrm{CH}_{2}$ ), 6.85-6.99 (multiplet, $4 \mathrm{H}$, aromatic $\mathrm{CH}$ ).

${ }_{13} \mathrm{C}$ Nuclear magnetic resonance (DMSO$\left.\mathrm{d}_{6}, 75 \mathrm{MHz}\right)$ : 68.42, 68.87, 69.79, 70.42, 113.92, 121.04, 148.63 .

Benzo-15-crown-5 synthesis (Synthesis 2: (adding tetraethyleneglycol dichloride in three equal parts).

The process is similar to Synthesis 1 (dropwise addition). The only difference is that tetraethyleneglycol dichloride was added to the reaction mixture by $52.2 \mathrm{ml}$ each 10 minutes.

Benzo-15-crown-5 synthesis (Synthesis 3: adding the whole amount of tetraethylenglycol dichloride).

The process is similar to Synthesis 1. The only difference is that $156.6 \mathrm{ml}$ tetraethyleneglycol dichloride was added to the reaction mixture at once.

Benzo-15-crown-5 synthesis (Synthesis 4: dropwise addition of tetraethyleneglycol dichloride to boiling reaction mixture).

The process is similar to Synthesis 1 . The only difference is that reaction mixture was heated to the boiling point prior to dichloride addition.
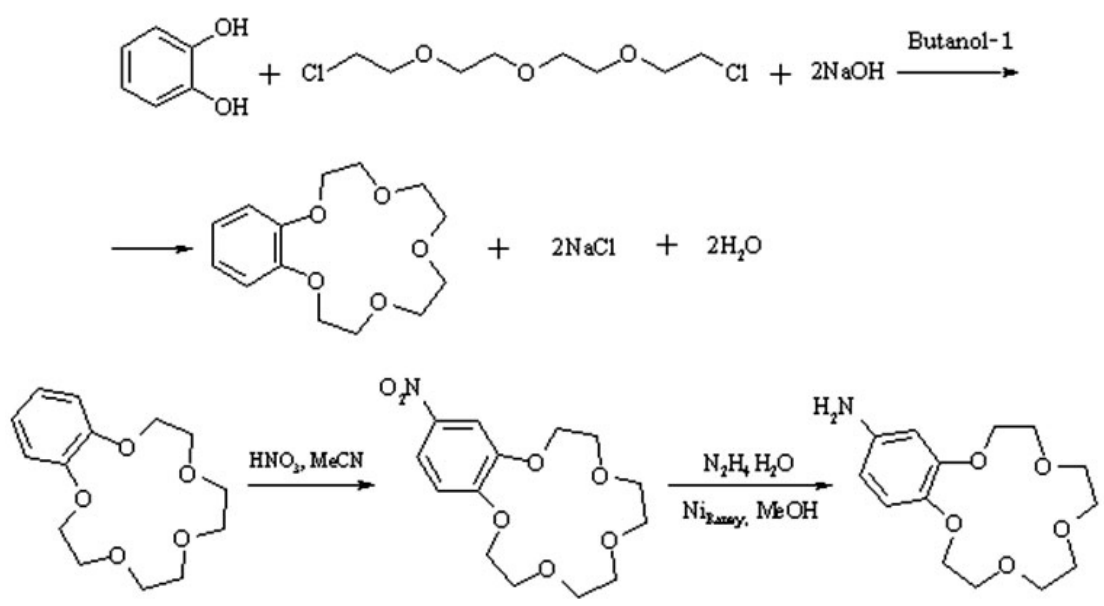

Fig.1: 4-aminobenzo-15-crown-5 synthesis scheme 
Benzo-15-crown-5 synthesis (Synthesis 5: adding tetraethyleneglycol dichloride to boiling reaction mixture in three equal parts).

The process is similar to Synthesis 2 . The only difference is that reaction mixture was heated to the boiling point prior to dichloride addition.

Benzo-15-crown-5 synthesis (Synthesis 3: adding the whole amount of tetraethyleneglycol dichloride to boiling reaction mixture).

The process is similar to Synthesis 2 . The only difference is that $156.6 \mathrm{ml}$ tetraethyleneglycol dichloride was added to the reaction mixture, which, in turn, was preheated to the boiling point.

Reaction flow monitoring was carried out using GLC method. Molar concentration values of target product within reaction mixture were determined using gas liquid chromatography (Table 1):

For the purpose of studying of the kinetics of benzo-15-crown-5 production process, reaction mass sampling was carried out at fixed time intervals, using alcohol solution of hydrochloric acid as a stop reagent $(\mathrm{pH}=3-4)$.

Quantitative sample analysis was carried out using gas liquid chromatography (GLC), which, in turn, was performed using gas chromatograph «Chromatec Crystal 5000.2», equipped with flame ionization detector and 30-m long fused silica column BP-5, with its inner diameter and fixed-phase film thickness of $0.32 \mathrm{~mm}$ and $0.5 \mu \mathrm{m}$ respectively. Carrier has: helium (rate: 2.8 $\mathrm{ml} / \mathrm{min}$, split ratio: $1: 25$, column temperature range: $150-300^{\circ} \mathrm{C}$, temperature setting: $10^{\circ} \mathrm{C} / \mathrm{min}$. Concentration values of sample components were calculated using percentage normalization per area.

\section{4-Nitrobenzo-15-crown-5 production (NB15C5)}

Benzo-15-crown-5 nitration was carried out by nitric acid, $58 \%$, over boiling reaction mass in the acetonitrile media, using relevant method $^{17}$.

Nitric acid of various concentrations can be used in nitration reaction. In some cases, diluted nitric acid (which is poor nitration agent and quite strong oxidizing agent) is also used due to the constant presence of nitrous acid that hinders nitration. Another drawback of diluted nitric acid, which limits its use, is its ability to express nitrating effect only at high temperatures, which are featured by prevailing side oxidation reaction. Concentrated nitric acid shows nitrating effect at lower temperatures and less likely to cause undesirable oxidation, which is why we carried out a nitration of resulted benzo-15-crown-5 with nitric acid, $56 \%$, in the acetonitrile media. The yield of target product was $99.5 \%$, while the melting point of resulted compound was $94-95^{\circ} \mathrm{C}$.

Infrared spectrum $\left(\mathrm{KBr}, v, \mathrm{~cm}^{-1}\right): 497$ (weak), 538 (weak), 618 (weak), 654 (medium) (aromatic C-H), 723 (weak), 745 (medium) $\left(\mathrm{NO}_{2}\right)$, 787 (weak), 806 (medium), 868 (medium) (N-O), 913 (weak), 934 (medium), 980 (medium), 1010(weak), 1047 (medium), 1093 (strong) (C-N), 1138 (strong) (C-O-C), 1240 (strong) $\left(\mathrm{NO}_{2}\right), 1276$ (strong) $\left(\mathrm{NO}_{2}\right)$, 1335 (strong) ( $\left.\mathrm{NO}_{2}\right), 1417$ (strong), 1428 (strong), 1448 (medium) $(\mathrm{N}=\mathrm{O}), 1517$ (strong) $\left(\mathrm{CH}_{2}+\mathrm{NO}_{2}\right)$, 1587 (medium) (aromatic C-C), 2868 (medium) (C-H), 2904 (medium) (C-H), 2929 (medium) (C-H), 3083 (medium) (aromatic $\mathrm{C}-\mathrm{H})$.

${ }_{1} \mathrm{HNuclear}$ magnetic resonance (DMSO-d ${ }_{6}, 300 \mathrm{MHz}$ ): 3.62 (broad singlet, $8 \mathrm{H}$, $\mathrm{CH}_{2}+\mathrm{CH}_{2}+\mathrm{CH}_{2}+\mathrm{CH}_{2}$ ), 3.74-3.85 (multiplet, $4 \mathrm{H}$, $\mathrm{CH}_{2}+\mathrm{CH}_{2}$ ), 4.13-4.24 (multiplet, $4 \mathrm{H}, \mathrm{CH}_{2}+\mathrm{CH}_{2}$ ), 7.15 (doublet, $1 \mathrm{H}, \mathrm{J}=8.9, \mathrm{CH}$ ), 7.73 (doublet, $1 \mathrm{H}, \mathrm{J}=2.7$, $\mathrm{CH}$ ), 7.89 (double doublet, $1 \mathrm{H}, \mathrm{J}=8.9, \mathrm{~J}=2.7, \mathrm{CH}$ ).

${ }_{13} \mathrm{C}$ Nuclear magnetic resonance (DMSO- $\mathrm{d}_{6}$, $75 \mathrm{MHz}): 67.77,68.84,69.27,69.71,70.09,70.16$, $70.30,100.96,105.53,117.49,139.35,143.95$, 149.92 .

\section{4-Aminobenzo-15-crown-5(AB15C5) production}

For the purpose of 4-nitrobenzo-15-crown-5 reducition we chose the method of reduction by hydrazine hydrate over skeleton Raney nickel catalyst in the alcohol media as the most convenient and effective one. Contrary to other methods, a reduction by hydrazine hydrate over nickel catalyst takes place at normal pressure and without autoclave.

$5 \mathrm{~g}$ Raney nickel was added to $34 \mathrm{~g}(0.108$ mole) 4-nitrobenzo-15-crown-5 with in 200-ml ethyl 
alcohol and heated to $500{ }^{\circ} \mathrm{C}$, followed by dripping $34 \mathrm{ml}$ hydrazine hydrate. In one hour's time it was filtered off the catalyst, with solution boiled out and residue recrystallized from $30-\mathrm{ml}$ ethyl alcohol. The yield of $\mathrm{AB} 15 \mathrm{C} 5$ was $70 \%$, with its melting point of 79.5-80.5 ${ }^{\circ} \mathrm{C}$

Infrared spectrum $\left(\mathrm{KBr}, \mathrm{v}, \mathrm{cm}^{-1}\right): 497$ (weak), 581 (weak), 631 (weak), 712 (weak), 766 (weak), 793 (weak) $\left(\mathrm{NH}_{2}\right), 847$ (medium) $\left(\mathrm{NH}_{2}\right)$, 917 (weak), 940 (medium), 987 (medium), 1060 (medium) (C-O-C), 1079 (medium), 1127 (strong) (C-O-C), 1181 (medium), 1217 (medium) (C-N), 1251 (medium), 1294 (medium), 1332 (weak), 1355 (weak), 1452 (medium), 1511 (strong) $\left(\mathrm{CH}_{2}\right)$, 1589 (weak) (aromatic C-C), 1610 (medium) $\left(\mathrm{NH}_{2}\right)$, 2878 (medium) (C-H), 2921 (medium) (C-H), 2957 (medium) (C-H), 3056 (aromatic $\mathrm{C}-\mathrm{H}), 3346$ (strong) $\left(\mathrm{NH}_{2}\right), 3396$ (strong) $\left(\mathrm{NH}_{2}\right)$.

1HNuclear@magnetic resonance $\left(\mathrm{DMSO}-\mathrm{d}_{6}, 300 \mathrm{MHz}\right.$ ): 3.60 (broad singlet, $8 \mathrm{H}$, $\mathrm{CH}_{2}+\mathrm{CH}_{2}+\mathrm{CH}_{2}+\mathrm{CH}_{2}$ ), 3.68-3.77 (multiplet, $4 \mathrm{H}$, $\mathrm{CH}_{2}+\mathrm{CH}_{2}$ ), 3.85-3.97 (multiplet, $4 \mathrm{H}, \mathrm{CH}_{2}+\mathrm{CH}_{2}$ ), 4.67 (broad singlet, $2 \mathrm{H}, \mathrm{NH}_{2}$ ), 6.05 (double doublet, $1 \mathrm{H}$, $\mathrm{J}=8.4, \mathrm{~J}=2.5, \mathrm{CH}$ ), 6.22 (doublet, $1 \mathrm{H}, \mathrm{J}=2.5, \mathrm{CH}$ ), 6.63 (doublet, $1 \mathrm{H}, \mathrm{J}=8.4, \mathrm{CH}$ ).

13C Nuclear magnetic resonance (DMSO$\mathrm{d}_{6}, 75 \mathrm{MHz}$ ): 67.77, 68.84, 69.27, 69.71, 70.09, $70.16,70.30,100.96,105.53,117.49$, 139.35, 143.95, 149.92.

\section{RESULTS AND DISCUSSION}

Reaction products were identified using gas chromatograph «Chromatec Crystal 500.2», equipped with mass spectrometry detector ThermolSQ and $15 \mathrm{~m}$ long fused silica column TR-5MS, with its inner diameter and fixed-phase film thickness of $0.25 \mathrm{~mm}$ and $0.25 \mu \mathrm{m}$ respectively. Carrier has: helium (rate: $2.8 \mathrm{ml} / \mathrm{min}$, split ratio: $1: 25$, column temperature range: $150-280^{\circ} \mathrm{C}$, temperature setting: $20{ }^{\circ} \mathrm{C} / \mathrm{min}$. Mass spectrums of an electronic impact were determined at the $70-\mathrm{eV}$ energy of ionizing electrons and $280{ }^{\circ} \mathrm{C}$ temperature of ion source. Reaction products were identified mainly by comparing registered spectrum with that of NISTUSA (2008) and also by molecular ion based on the correlation between mass, spectrum and structure.

\section{Reaction products were identified using chromate-mass spectrometry}

It was found out that there were two impurities, identified as compounds $A$ and $B$, which formed alongside with benzo-15-crown-5.The formation of impurity $A$ was the result of tetraethylene glycol dichloride hydrolysis, while impurity B was 2-(2-(2-(2-(2-chlorethoxy)ethoxy)ethoxy)ethoxy) phenol. Structural formulas of these side products are shown in Figures 2 and 3 below.

In case of Synthesis 1, apart from target product (i.e. benzo-15-crown-5 (80.09\%)), intermediate and side products, the reaction mixture also contained initial catechol and tetraethylene glycol dichloride $(4.149 \%$ and $8.106 \%$ respectively) at $6.5 \mathrm{~h}$, time after the reaction had started. As synthesis duration increased to $8.5 \mathrm{~h}$, the content of target product reached $82.097 \%$, with its further formation taking place at extremely low rate.

In case of tetraethylene glycol dichloride addition in three equal parts every 10 minutes, the concentration of target product under the same conditions was $80.192 \%$. In case of adding the whole amount of tetraethylene glycol dichloride at once, the concentration of target product was $78.431 \%$.

The curve of dependence between reaction mixture and synthesis duration 1 is shown in Figure 4.

Thus, benzo-15-crown-5 forms only after reaction mixture has been heated to its boiling point $\left(107^{\circ} \mathrm{C}\right)$, which takes $1.3 \mathrm{~h}$. Then, the temperature of reaction mixture decreases to $102{ }^{\circ} \mathrm{C}$, followed by formation of two side products, $A$ and $B$, in comparatively small quantities (4.211\% and $3.554 \%$ respectively).

Benzo-15-crown-5 is extracted from boiling reaction mass by hexane. The mass fraction of<smiles>OCCOCCOCCOCCCl</smiles>

Fig. 2: 1-chlorine-11-hydroxytetraethyleneglycol, m/z 212.5<smiles>Oc1ccccc1OCCOCCOCCOCCCl</smiles>

Fig. 3: 2-(2-(2-(2-(2-chlorethoxy)ethoxy)ethoxy) ethoxy)phenol, $\mathrm{m} / \mathrm{z} 304.11$ 
resulted product's basic substance was $98 \%$, with its melting point of $79.5-80.5^{\circ} \mathrm{C}$.

Given the kinetics of Sythesis 1, we assumed that TEGDC addition to boiling reaction mixture should accelerate the formation of crown ether and increase its yield. However, this assumption proved to be wrong, since dropwise addition of tetraethyleneglycol dichloride to boiling reaction mixture resulted in target product's concentration after $7 \mathrm{~h}$ boiling of $72.902 \%$, which was $9.195 \%$ lower than that of similar synthesis with TEGDC addition not accompanied by boiling. In case of adding TEGDC in three parts, the concentration of target product was $65.482 \%$. In case of adding the whole amount of TEGDC at once, the concentration of target product was $58.934 \%$.

Thus, the best conditions for benzo-15crown- 5 synthesis among the above-mentioned ones are adding tetraethyleneglycol dichloride to unboiled reaction mass.

The chosen methods for the preparation of nitro- and amino-derivatives of benzo-15-crown-5 make it possible to obtain the above-mentioned functional crown ethers with high yields and high quality.

Differential thermal analysis was used for determining melting points and analyzing thermal decomposition process of B15C5, NB15C5 and AB15C5. TGA (thermo-gravimetric analysis) and DSC (differential scanning calorimetry) methods, as well as combined simultaneous thermal analyzer STD Q600 (manufacturer: TA Instruments (USA)) were used in these study. Measurements were carried out in air (flow rate: $100 \mathrm{ml} / \mathrm{min}$.) inside alundum crucibles, with the heating rate of $10^{\circ} \mathrm{C} / \mathrm{min}$. and the temperature ranging from room temperature to $300^{\circ} \mathrm{C}$.

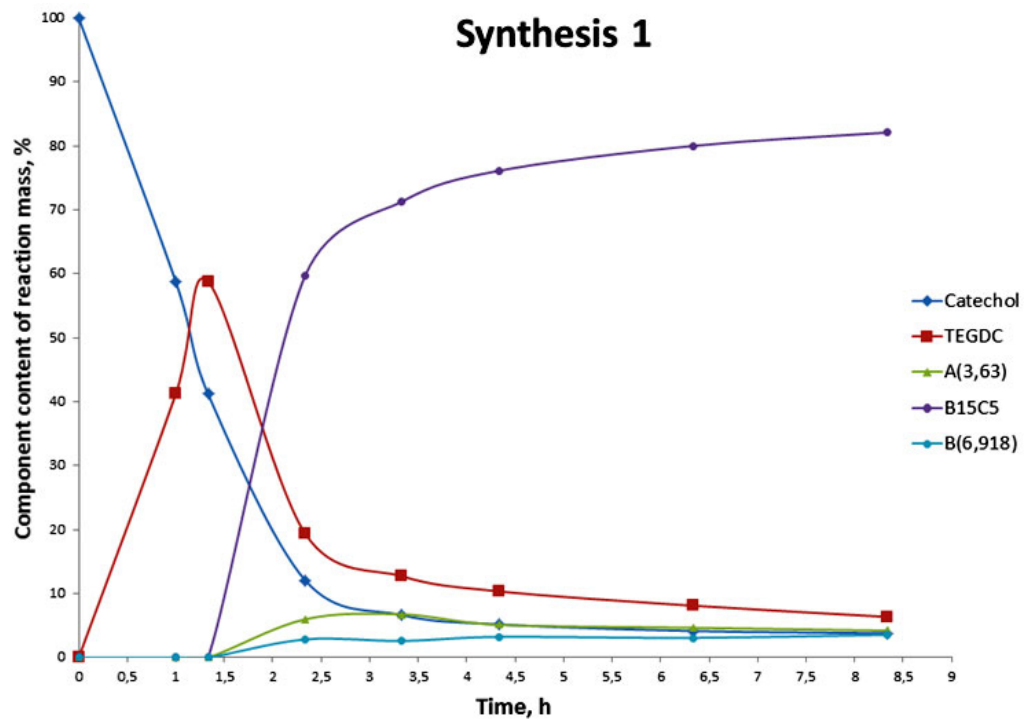

Fig. 4: Dependence between reaction mixture composition and duration of Synthesis 1

Table 1 Target product percentage of the reaction mixture depending on reaction conditions

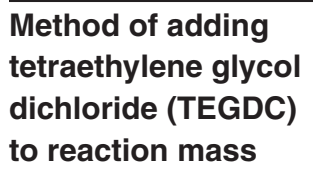

B15C5 content of reaction mass, $\%$

TEGDC addition to TEGDC addition at
boiling reaction mass
Dropwise TEGDC

1/3 of TEGDC amount every ten minutes

Full amount of TEGDC at once
82.097

80.192

78.431
72.902

65.482

58.934 


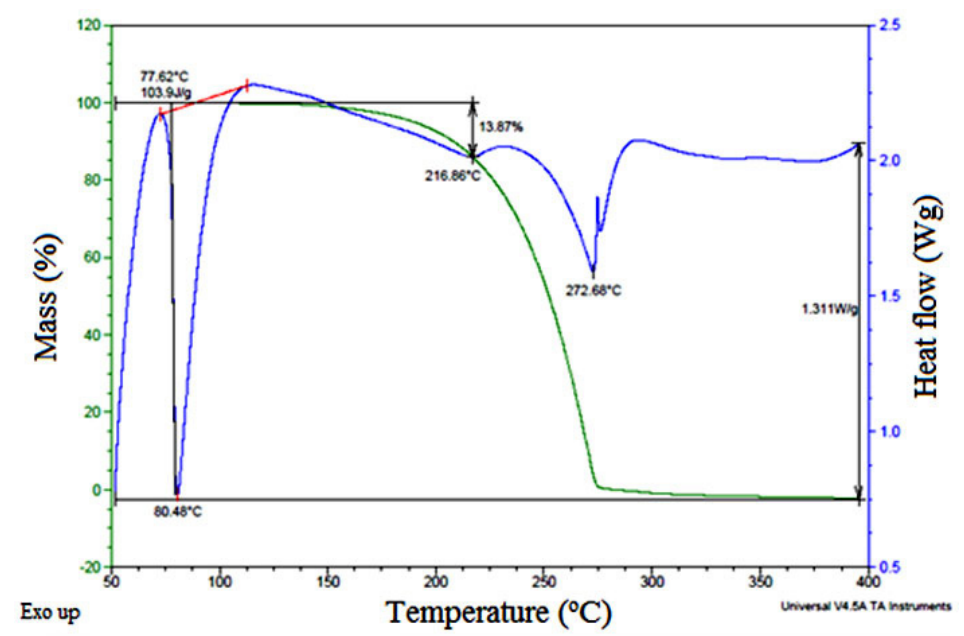

Fig. 5: B15C5 thermograph

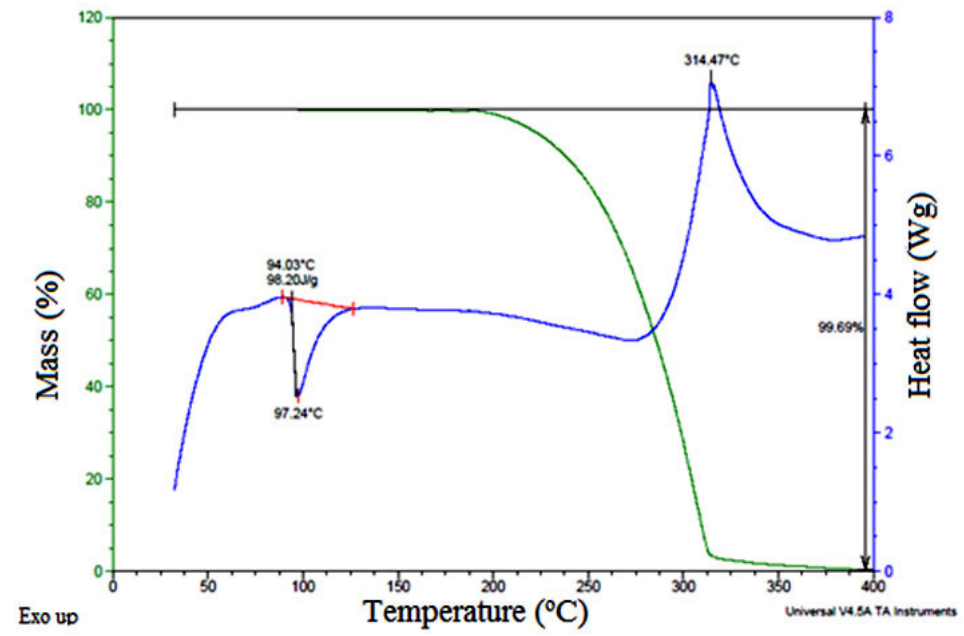

Fig. 6: NB15C5 thermograph

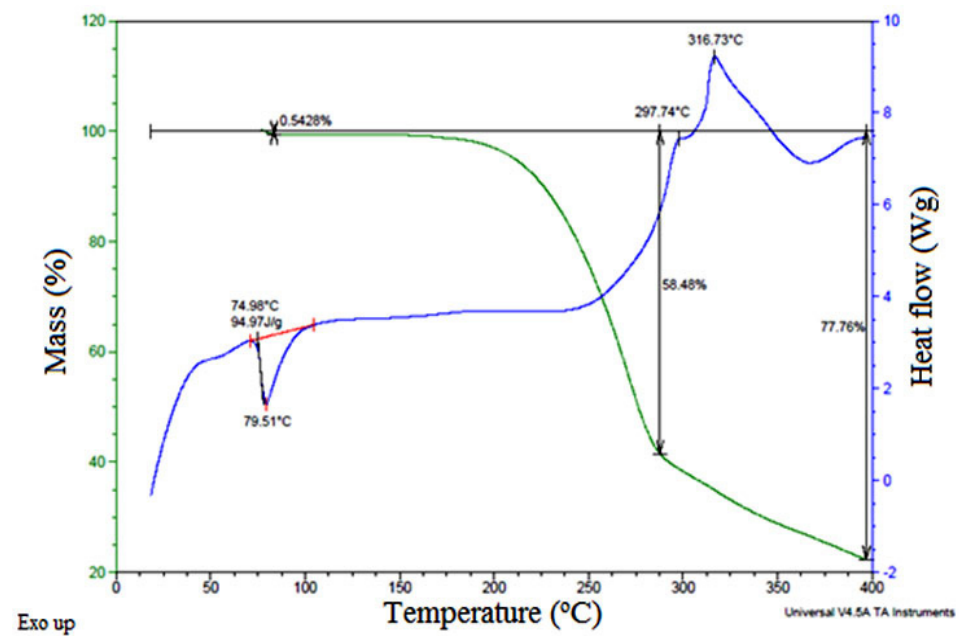

Fig. 7: AB15C5 thermograph 
Thermal decomposition of crown-ethers is a complicated and staged process which comprises 2 stages: compound melting, which takes place at temperatures of up to $100^{\circ} \mathrm{C}$, compound decomposition, which begins within temperature range of $150-175^{\circ} \mathrm{C}$.

Figure 5 shows the thermograph of sample. An endothermic peak at a temperature $\mathrm{B} 15 \mathrm{C} 5$ of about $80{ }^{\circ} \mathrm{C}$, not accompanied by massive changes, means the melting process. Decomposition begins at $150{ }^{\circ} \mathrm{C}$, with $14 \%$ mass loss at the first stage. At $217^{\circ} \mathrm{C}$ decomposition process accelerates and lasts until the whole mass is lost. There is a narrow exothermic peak at $274{ }^{\circ} \mathrm{C}$, which point to possible ignition of the substance.

Figure 6 shows the thermograph of sample. An endothermic peak at a temperature NB15C5 of about $97^{\circ} \mathrm{C}$, not accompanied by massive changes, means the melting process. An exothermic peak at a temperature of about $314^{\circ} \mathrm{C}$, accompanied by complete loss of mass, points to sample combustion during decomposition process.

Figure 7 shows the thermograph of sample. An endothermic peak at a temperature AB15C5 of about $97{ }^{\circ} \mathrm{C}$, accompanied by $0.5 \%$ massive loss, points to a water loss process taking place alongside melting. The decomposition of this sample is complicated and comprises two stages. At the first stage, there is a rapid mass loss of $58 \%$ within the temperature range of $170-297^{\circ} \mathrm{C}$. Then the process slows down, with $77.7-\%$ loss of sample mass at the temperature of $400^{\circ} \mathrm{C}$.

Differential thermal analysis was used for determination of melting points and analysis of thermaldecomposition process of B15C5, NB15C5 and AB15C5. TGA (thermo-gravimetric analysis) and
DSC (differential scanning calorimetry) methods, as well as combined simultaneous thermal analyzer STD Q600 (manufacturer: TA Instruments (USA)) were used in the study. Measurements were carried out in air (flow rate: $100 \mathrm{ml} / \mathrm{min}$.) inside alundum crucibles, with the heating rate of $10^{\circ} \mathrm{C} / \mathrm{min}$. and the temperature ranging from room temperature to $300{ }^{\circ} \mathrm{C}$

As it was shown, the melting point of $\mathrm{B} 15 \mathrm{C} 5$ was $80.48^{\circ} \mathrm{C}$. Sample mass is reduced by $0.04 \%$ in the course melting process. In case of NB15C5, melting point and mass loss were $97.24{ }^{\circ} \mathrm{C}$ and $0.44 \%$ respectively. In case of $A B 15 C 5$, melting point and mass loss were $79.51^{\circ} \mathrm{C}$ and $0.53 \%$.

\section{CONCLUSION}

The study has shown that tetraethyleneglycol dichloride addition to the reaction mixture at the rate of $17 \mathrm{ml} / \mathrm{min}$. results in benzo-15-crown-5 content reaching $82.097 \%$ of reaction mass. At the same time, we that 7 hours were proved as an optimal dwell time at the boiling point, which allows to reduce the reaction duration by 23 hours, comparing with the conventional method. It has also been found that it is possible to carry out the reduction of nitrobenzo-15-crown- 5 by using hydrazine hydrate over Raney nickel at normal atmospheric pressure. Thermogravimetric properties of resulted products have been determined.

\section{ACKNOWLEDGMENTS}

The applied researches are carried out with state financial support represented by the Ministry of Education of Russia under the Agreement on granting subsidies $\mathrm{N}^{0}$ (number)14.625.21.0034 of October 27, 2015. (Unique identifier of Applied Scientific Researche (project) RFMEFI62515X0034).

\section{REFERENCES}

1. Steed, J.W.; Atwood, J.L. Supramol. Chem.2007,1, 121-126

2. Hiraoka, M. Crown compounds. Properties and application. Moscow, Mir, 1986

3. Yatsimirsky, K.B.; Kolchinsky, A.G.; Pavlishuk, V.V.; Talanova, G.G. Synthesis of macrocyclic compounds. Kyiv, Naukova Dumka, 1987

4. Marijeta, K.; Ljerka, T.; Frkanec, L. Chem. Med. Chem.2008, 3, 1478-1492

5. Pliego, J. R.; Riveros, J.M. J. Mol. Catal. A:Chem. 2012, 15(4), 489-494

6. Rounaghi, G.; Eshghi, H. Arab. J. Chem.2012, 
17(7), 378-379

7. Yu, H.-R.; Ju, X.-J.; Xie, R.; Wang, W.; Zhang, B.; Chu, L.-Y. Anal. Chem.2013. 85(13), 64776484

8. Bogatsky, A.; Lukyanchenko, N. Fiziologiya Rasteniy.1984, 6, 1015-1020

9. Amiran, M.C. Chemical cleaning solution for gas turbine blades. Patent US 6310022 B1. 2001

10. Kotlyar,S.A.; Gorodnyuk,V.P.; Grigorash,R.Ya.; Chuprin,G.N. Russ. J. Gen. Chem.1998,68(7), 1189-1192

11. .Piatek, P.; Litwin, A. Tetrahedron.2009,65, 2285-2289

12. Shen, Y.C.; Shih J.S.J. Chin. Chem. Soc. 2008,55, 578-586

13. Sousa, C.; Gameiro, P.; Freire, C.; Castro, B. Polyhedron. 2004, 23, 1401-1408

14. Titova,Yu.A.; Fedorova,O.V.;Ovchinnikova,I.G.; Maksimovskikh,A.I.; Uimin,M.A.; Rusinov,G.L.; Charushin, V.N. Macroheterocycles.2014, 7(1), 23-27
15. Lowicki, D.; Huczynski, A.; Stefanska, J.; Brzezinski, B. Tetrahedron. 2011,67,14681478

16. Ungaro,R.; HajB. El.; Smid,J. J. Am. Chem. Soc. $1976,98,5198$

17. Ivanov,O.V.; Markevitch,I.S.; Blokhina,L.I.; Nikolaenko,S.P.; Filatova,M.P.; Vasilchenko,G.V. Preparation of mononitrobenzo-crown ethers. Patent USSR 1544774 A1.1990

18. Martyanov,T.P.; Ushakov,E.N.;Savelyev, V.A.;Klimenko, L.S.Russ. Chem. Bull., Intern. Ed.2012,61(12), 2261-2273

19. Deetz, M.J.; Shang, M.; Smith, B.D. J. Am. Chem. Soc.2000, 122, 6201-6207

20. Feigenbaum, W.M.; Michel, R.H. J. Polym. Scien. P. A-1: Polym. Chem.1971,9(3), 817820

21. Wang, D.; Xing, J.; Peng, J.; Wu, C. J.Chromatography A.2003, 1005, 1-12

22. Rossa, L.; Vögtle Fr.Chem. Med. Chem. 2014, 8(1),3-5 